\title{
Concurrence of multiple sclerosis and brain tumors
}

\section{Domenico Plantone*, Rosaria Renna, Emilia Sbardella and Tatiana Koudriavtseva}

Unit of Neurology, Multiple Sclerosis Center, Regina Elena National Cancer Institute, IFO, Rome, Italy

${ }^{*}$ Correspondence: domenicoplantone@hotmail.com

Edited by:

Hans-peter Hartung, Heinrich-Heine University Duesseldorf, Germany

Reviewed by:

Jorge Correale, Raúl Carrea Institute for Neurological Research (FLENI), Argentina

Wolfgang Brück, University Medical Center Göttingen, Germany

Keywords: multiple sclerosis, brain tumors, glioblastoma, oligodendroglioma, astrocytoma

\section{INTRODUCTION}

Multiple sclerosis (MS) is a chronic demyelinating inflammatory disease of the central nervous system (CNS) with multifactorial pathogenesis that includes genetic and environmental factors. A primary brain tumor is a neoplasm developing from the cells of the brain. There is high heterogeneity of primary brain tumors (about 100 different types); however, most of them develop from the glial cells.

Although several types of brain tumors have been widely described in association with MS (1-20), including astrocytoma $(5,9)$, oligodendroglioma $(12,17)$, and glioblastoma $(3,11,14,18)$, it is not clear whether their occurrence is accidental or consequent to causal events. Moreover, it is not completely defined if MS and brain tumors, when associated, have a different course. The true incidence of brain tumors in MS patients is difficult to define because the diagnosis of a brain tumor in MS patients may seem more frequent than in the general population due to frequent neuroimaging scans performed in these patients (21). At the same time, pseudotumoral MS lesions may resemble gliomas, and conversely, early stage gliomas may resemble MS. Brain tumors in MS patients may be diagnosed later or even postmortem (22), especially in patients with progressive MS, since the new symptoms may be attributed to the gradual clinical progression of MS rather than to the slow growing of tumor itself (23). A recent study reported that MS patients have a decreased overall cancer risk, but an increased risk for brain tumor (24). If immunosuppressive treatment for MS might promote cancerogenesis is still matter of debate, it is difficult to explain on this basis why MS patients have a decreased overall cancer risk and an increased risk only for brain and genitourinary tract tumors (24). A successive systematic analysis showed no increased or decreased risks for glioma in MS patients, while an increased risk was found for meningioma, as a result of incidental findings (25). Moreover, several autoimmune diseases influence negatively the survival in glioma and meningioma, likely due to pre-existent disability or treatment limitations (25).

\section{DIFFERENTIAL DIAGNOSIS BETWEEN MS AND BRAIN TUMORS}

A first issue emerging in case of concurrence of MS and brain tumors is the differential diagnosis since MS plaques may resemble gliomas and vice-versa (26). Although brain tumors associated with MS have their usual distribution at frontal and temporal lobes (27), the localization criteria are not helpful for the differential diagnosis. Therefore, the appearance of uncommon neurological symptoms in MS patients should suggest the need for more extensive investigations in order to exclude overlapping pathologies (28). In addition to brain tumors, the differential diagnosis of pseudo-tumoral brain lesions includes infectious, neoplastic (in particular primary CNS lymphomas and metastatic cancers), congenital, metabolic or vascular diseases, and non-MS idiopathic inflammatory demyelinating diseases as well (for instance, neuromyelitis optica, opticospinal MS in Asian populations, acute disseminated encephalomyelitis) (29). They differ from MS in course, pathophysiology, treatment, and prognosis. In 2008, the Task Force on Differential Diagnosis in MS has defined major, intermediate, and minor red flags consisted in informative symptoms, signs, and assays indicative, respectively, of nonMS diagnosis, uncertainty or possibility that an MS diagnosis is not excluded (29). The major red flags, for example, for lymphoma, are represented by persistent Gd-enhancement, continued enlargement of lesions, simultaneous enhancement of all lesions, marked asymmetry of white matter lesions, headache, or meningismus.

Among the diagnostic tools that have been proposed to differentiate MS from tumors, there are also some blood indicators such as inflammatory transcription factors of the peripheral blood mononuclear cells (18). However, they are more useful in expressing patients' immunological status than in making a proper differential diagnosis between MS and brain tumors. To date, the non-conventional MRI techniques such as spectroscopy, positron emission tomography, and CNS biopsy remain the most useful tools for the differential diagnosis.

\section{POSSIBLE CAUSAL RELATIONSHIP BETWEEN BRAIN TUMORS AND MS}

Whether the concurrence of MS and glioma may be explained by causal relationship or by coincidence is still matter of debate $(17,25)$. In 1973, it was observed that despite the rare concurrence of such relatively common conditions some pathological features, especially the frequent contiguous relationship between tumor and plaque, suggested a closer association between these pathologies (30). It was hypothesized that in some MS patients an unknown factor, hereditary or acquired, may stimulate the neoplastic transformation of reactive astrocytes. Moreover, it was supposed a causative role for a bipotential cytolytic-oncogenic agent such as Papova virus (30). Almost 20 years 
later, another study, based on the most extensive literature, came to similar conclusions (31). A transformation of a megaplaque into an ependymoma added new evidence in favor to a cause-effect relationship between MS and brain tumors (32). It can be hypothesized that MS lesions may transform into a tumor likely due to circumscribed increased proliferation ratio induced by MS remyelinating processes since the neurotropic growth factors promoting the proliferation and survival of oligodendrocytes have the beneficial effect on the clinical, pathological, and molecular manifestations of autoimmune demyelination in experimental models $(33,34)$. It was also found a re-expression of a developmental gene in chronic lesions with the highest levels of their products correlating with remyelination (35). The recapitulation of ontogenetic events during myelin repair has been supposed as normal adult CNS and non-MS material showed very low levels of such gene products, while fetal human CNS tissue showed high levels. Therefore, the possibility of common rare underlying genetic factors in both tumors and MS is possible, but so far there are no sufficient data to definitely confirm it. Furthermore, owing to high heterogeneity of primary brain tumors, the research on their genetic alterations is not simple. Interestingly, the recently identified MS risk genes mainly belong to the immune system (36), and alterations in innate immunity-related genetic regions have been associated with an increased risk of adult glioma (37). It may be also hypothesized that aberrant epigenetic mechanisms, such as DNA methylation and histone protein modifications, could be involved in both MS and tumor pathogenesis (38). Methylated gene promoters are silenced, while unmethylated ones can be active reflecting, albeit imprecisely, gene expression. Certain regions of the brain in MS patients show abnormally methylated genes with a specific profile or decreased methylation, for example, of cytosine of the gene encoding the myelin enzyme peptidylarginine deiminase-2 promoter in MS normal-appearing white matter (39). Still more, DNA methylation is altered in tumors and may represent a predictive factor of response to specific drugs. In particular, the O6-methylguanine-DNA methyltransferase promoter hypermethylation was found to be strongly associated with partial or complete clinical response (40-42). However, no possible causal epigenetic mechanisms between brain tumors and MS could be inferred by these limited data.

Finally, it is possible to speculate that a common viral agent is involved in the pathogenesis of these diseases. After 30 years from the first supposition of a possible Papova virus role in both disorders (30), the post-mortem examination of an immunocompetent patient with MS plaques and a glioblastoma multiforme provided molecular evidence of the association of human polyomavirus JC virus (JCV) of Papova virus family with these concurrent pathologies (14). PCR analysis revealed the presence of viral DNA in demyelinated plaques and within the tumor, while immunohistochemistry showed the detection of the viral early protein, T-antigen, and the cellular tumor suppressor protein, p53, only in the nuclei of neoplastic cells. Conversely, the expression of T-antigen, but not of p53, was observed in astrocytes and neuronal cells of the cortex juxtaposed to the MS plaque. No productive replication of JCV was identified in both tumor and MS lesions since the examination of viral late gene expression by immunohistochemistry showed no evidence for viral capsid proteins. Furthermore, some authors detected the presence of JCV in samples derived from several types of neural and non-neural human tumors (43-50), and several studies highlighted its potential role in a broad range of animal models and human carcinogenesis (51-54).

JC virus was identified as the etiologic agent of progressive multifocal leukoencephalopathy, first diagnosed only in immunocompromised patients or those suffering from leukemia, but now representing a serious complication of Natalizumab treatment in MS $(55,56)$. JCV is very common in the general population infecting $70-90 \%$ of humans (57), and a higher rate of JCV seroconversion compared to than expected has been observed in MS patients treated with Natalizumab (58). JC viral genome has been detected in normal brain tissue (59), therefore, the latent JCV-DNA antigens expressed at low levels in the CNS have been proposed as possible targets of pathogenetic immune response in MS (60). Initially, the JCV-DNA was found neither in the urine (61) nor in the brain tissue (62) of MS patients. However, more recent studies showed the presence of JCV-DNA in both CSF $(63,64)$ and blood $(65)$ in MS patients (although in a low percentage) and not in controls.

Moreover, novel clinical entities without typical PML lesions caused by JCV variants infecting cerebellar granule cell neurons and cortical pyramidal neurons as well as JCV meningitis have been recently discovered (66).

Therefore, JCV might be a feasible etiological candidate for both MS and brain tumors due to its ability to persist in the latent state mainly in myelin-producing oligodendrocytes and to its oncogenic capacity. However, JCV presence might still simply reflect the subclinical immunodeficiency of cancer patients or MS patients treated with immunosuppressive drugs.

\section{THERAPY OF ASSOCIATED MS AND BRAIN TUMORS}

There are no trials on the treatment of associated cases of MS and brain tumors owing to their rarity. The data here reported represent case reports and experimental observations.

It should not seem strange that the immunosuppressive treatments given for neoplasms may reduce disease activity in MS. In a patient of ours with MS and oligodendroglioma, MS activity significantly reduced both clinically and at MRI during the 2-year treatment with temozolomide (personal unpublished data).

Although the safety of radiotherapy for MS course was described in one case report (67), the negative effects of surgery and radiotherapy on MS, due to the liberation of brain-specific antigens triggering disimmune reactions, have also been reported (68). A vast review on MS relapses considered cranial radiation as their promoting factor (69).

Furthermore, a sphingosine analog FTY720, which downregulates the expression of sphingosine-1-phosphate receptors, is not only effective in MS (70) but also causes in vitro apoptosis of brain tumor stem cells derived from human glioblastoma tissue (71). Also dimethyl-fumarate, demonstrated to be effective in treatment of MS (72), appears to act on malignant brain neoplasms in vitro by reducing 
the proliferation rate, generating cell lysis, decreasing the expression of NF- $\kappa \mathrm{B}$, and restricting the growth of CD133 cells in gliomas (73).

\section{CONCLUSION}

Although the co-existence of MS and brain tumors has been long described, many doubts regarding their possible causal association persist. JCV is of significant interest in this issue due to its ability to latent persist in the CNS and to its experimental neurooncogenic potential. Since MS is caused by putative CNS autoimmune mechanisms whereas brain neoplasms may be dependent on a subclinical immunosuppressive state, these pathologies can coexist only in particular situations. It can be hypothesized that these conditions may occur during the remyelinating processes coinciding with a decline of the CNS immune reaction and with the production of growth factors in the effort to repair the damage, thus favoring a hypothetical JCV-related cell neoplastic transformation in genetically or environmentally induced susceptible individuals. Studying with special care, the patients affected by both diseases, which apparently locate at the opposite ends of immunosurveillance, could allow to find the key to their pathogenesis.

\section{REFERENCES}

1. Brihaye J, Perier O, Stenuit J. Multiple sclerosis associated with a cerebral glioma. J Neuropathol Exp Neurol (1963) 22:128-37. doi:10. 1097/00005072-196301000-00009

2. Currie S, Urich H. Concurrence of multiple sclerosis and glioma. J Neurol Neurosurg Psychiatry (1974) 37:598-605. doi:10.1136/jnnp.37.5.598

3. Lahl R. Combination of multiple sclerosis and cerebral glioblastoma. Eur Neurol (1980) 19:192-7. doi:10.1159/000115146

4. Giordana MT, Mauro A, Soffietti R, Leone M. Association between multiple sclerosis and oligodendroglioma. Case report. Ital J Neurol Sci (1981) 2:403-9.

5. Ho KL, Wolfe DE. Concurrence of multiple sclerosis and primary intracranial neoplasms. Cancer (1981) 47:2913-9. doi: 10.1002/1097-0142 (19810615)47:12<2913::AID-CNCR2820471229> 3.0.CO;2-1

6. Abbott RJ, Howe JG, Currie S, Holland I. Multiple sclerosis plaque mimicking tumour on computed tomography. Br Med J (Clin Res Ed). (1982) 285:1616-7. doi:10.1136/bmj.285.6355.1616

7. Malmgren RM, Detels R, Verity MA. Cooccurrence of multiple sclerosis and glioma - case report and neuropathologic and epidemiologic review. Clin Neuropathol (1984) 3:1-9.

8. Vieregge P, Nahser HC, Gerhard L, Reinhardt V, Nau HE. Multiple sclerosis and cerebral tumor. Clin Neuropathol (1984) 3:10-21.
9. Röyttä M, Latvala M. Diagnostic problems in multiple sclerosis. Two cases with clinical diagnosis of MS showing only a diffusely growing malignant astrocytoma. Eur Neurol (1986) 25:197-207.

10. Nahser HC, Vieregge P, Nau HE, Reinhardt V. Coincidence of multiple sclerosis and glioma. Clinical and radiological remarks on two cases. Surg Neurol (1986) 26:45-51. doi:10.1016/0090-3019(86) 90062-5

11. Aarli JA, Mørk SJ, Myrseth E, Larsen JL. Glioblastoma associated with multiple sclerosis: coincidence or induction? Eur Neurol (1989) 29:312-6. doi:10.1159/000116437

12. Khan OA, Bauserman SC, Rothman MI, Aldrich EF, Panitch HS. Concurrence of multiple sclerosis and brain tumor: clinical considerations. Neurology (1997) 48:1330-3. doi:10.1212/WNL.48.5.1330

13. Hemminki K, Li X, Plna K, Granström C, Vaittinen P. The nation-wide Swedish familycancer database - updated structure and familial rates. Acta Oncol (2001) 40:772-7. doi:10.1080/ 02841860152619214

14. Del Valle L, Delbue S, Gordon J, Enam S, Croul S, Ferrante P, et al. Expression of JC virus T-antigen in a patient with MS and glioblastoma multiforme. Neurology (2002) 58(6):895-900. doi:10. 1212/WNL.58.6.895

15. Shuangshoti S, Hjardermaal GM, Ahmad Y, Arden JL, Herman MM. Concurrence of multiple sclerosis and intracranial glioma. Report of a case and review of the literature. Clin Neuropathol (2003) 22:304-8.

16. Khan SH, Buwembo JE, Li Q. Concurrence of glioma and multiple sclerosis. Can J Neurol Sci (2005) 32:349-51. doi:10.1017/ S031716710000425X

17. Sega S, Horvat A, Popovic M. Anaplastic oligodendroglioma and gliomatosis type 2 in interferonbeta treated multiple sclerosis patients. Report of two cases. Clin Neurol Neurosurg (2006) 108:259-65. doi:10.1016/j.clineuro.2005.11.015

18. Frisullo G, Patanella AK, Nociti V, Cianfoni A, Iorio $\mathrm{R}$, Bianco A, et al. Glioblastoma in multiple sclerosis: a case report. J Neurooncol (2009) 94:141-4. doi:10.1007/s11060-009-9804-9

19. Hinnell C, Almekhlafi M, Joseph JT, Bell R, Sharma P, Furtado S. Concurrence of highgrade brainstem glioma and multiple sclerosis. Can J Neurol Sci (2010) 37:512-4. doi:10.1017/ S0317167100010556

20. Koudriavtseva T, Onesti E, Pace A, Carapella C, Vidiri A, Anelli V, et al. Differential diagnosis between demyelinating syndrome and glioma: our clinical case study. Neurol Sci (2010) 31(Suppl):S282.

21. Montgomery S, Hassan A, Bahmanyar S, Brus O, Hussein O, Hiyoshi A, et al. Mortality following a brain tumour diagnosis in patients with multiple sclerosis. BMJ Open (2013) 3:e003622. doi:10.1136/bmjopen-2013-003622

22. Pál E, Gömöri EE, Gáti I. Neurofibromatosis and glioblastoma in a case of multiple sclerosis. Eur J Neurol (2001) 8:717-8. doi:10.1046/j.1468-1331. 2001.00320.x

23. Werneck LC, Scola RH, Arruda WO, Torres LF. Glioma and multiple sclerosis: case report. Arq Neuropsiquiatr (2002) 60:469-74. doi:10.1590/ S0004-282X2002000300024
24. Bahmanyar S, Montgomery SM, Hillert J, Ekbom A, Olsson T. Cancer risk among patients with multiple sclerosis and their parents. Neurology (2009) 72:1170-7. doi:10.1212/01.wnl. 0000345366.10455 .62

25. Hemminki K, Liu X, Försti A, Ji J, Sundquist J, Sundquist K. Subsequent brain tumors in patients with autoimmune disease. Neuro Oncol (2013) 15:1142-50. doi:10.1093/neuonc/not070

26. Hunter SB, Ballinger WE Jr, Rubin JJ. Multiple sclerosis mimicking primary brain tumor. Arch Pathol Lab Med (1987) 111:464-8.

27. Green AJ, Bollen AW, Berger MS, Oksenberg JR, Hauser SL. Multiple sclerosis and oligodendroglioma. Mult Scler (2001) 7:269-73. doi:10. $1191 / 135245801680209394$

28. da Silva AA, dos Santos Cavaco SM, Taipa RJ, Pinto PR, Pires MJ. Medulloblastoma and gliomatosis cerebri: rare brain tumors in multiple sclerosis patients. Neurol Sci (2011) 32:893-7. doi:10.1007/ s10072-010-0468-1

29. Miller DH, Weinshenker BG, Filippi M, Banwell BL, Cohen JA, Freedman MS, et al. Differential diagnosis of suspected multiple sclerosis: a consensus approach. Mult Scler (2008) 14(9):1157-74. doi: $10.1177 / 1352458508096878$

30. Reagan TJ, Freiman IS. Multiple cerebral gliomas in multiple sclerosis. J Neurol Neurosurg Psychiatry (1973) 36:523-8. doi:10.1136/jnnp.36.4.523

31. Shankar SK, Rao TV, Srivastav VK, Narula S, Asha T, Das S. Balo's concentric sclerosis: a variant of multiple sclerosis associated with oligodendroglioma. Neurosurgery (1989) 25(6):982-6. doi:10.1097/00006123-198912000-00024

32. Acqui M, Caroli E, Di Stefano D, Ferrante L. Cerebral ependymoma in a patient with multiple sclerosis case report and critical review of the literature. Surg Neurol (2008) 70:414-20. doi:10.1016/j. surneu.2007.04.015

33. Cannella B, Hoban CJ, Gao YL, Garcia-Arenas $\mathrm{R}$, Lawson D, Marchionni M, et al. The neuregulin, glial growth factor 2, diminishes autoimmune demyelination and enhances remyelination in a chronic relapsing model for multiple sclerosis. Proc Natl Acad Sci U S A (1998) 95:10100-5. doi:10.1073/pnas.95.17.10100

34. Villoslada P, Hauser SL, Bartke I, Unger J, Heald $\mathrm{N}$, Rosenberg D, et al. Human nerve growth factor protects common marmosets against autoimmune encephalomyelitis by switching the balance of $\mathrm{T}$ helper cell type 1 and 2cytokines within the central nervous system. J Exp Med (2000) 191:1799-806. doi:10.1084/jem.191.10.1799

35. Capello E, Voskuhl RR, McFarland HF, Raine CS. Multiple sclerosis: re-expression of a developmental gene in chronic lesions correlates with remyelination. Ann Neurol (1997) 41(6):797-805. doi:10.1002/ana.410410616

36. International Multiple Sclerosis Genetics Consortium. Network-based multiple sclerosis pathway analysis with GWAS data from 15,000 cases and 30,000 controls. Am J Hum Genet (2013) 92(6):854-65. doi:10.1016/j.ajhg.2013.04.019

37. Rajaraman P, Brenner AV, Butler MA, Wang SS, Pfeiffer RM, Ruder AM, et al. Common variation in genes related to innate immunity and risk of adult glioma. Cancer Epidemiol Biomarkers Prev (2009) 18(5):1651-8. doi:10.1158/1055-9965.EPI08-1041 
38. Urdinguio RG, Sanchez-Mut JV, Esteller M. Epigenetic mechanisms in neurological diseases: genes, syndromes, and therapies. Lancet $\mathrm{Neu}$ rol (2009) 8(11):1056-72. doi:10.1016/S14744422(09)70262-5

39. Mastronardi FG, Noor A, Wood DD, Paton T, Moscarello MA. Peptidyl argininedeiminase 2 CpG island in multiple sclerosis white matter is hypomethylated. J Neurosci Res (2007) 85(9):2006-16. doi:10.1002/jnr.21329

40. Hegi ME, Diserens AC, Godard S, Dietrich PY, Regli L, Ostermann S, et al. Clinical trial substantiates the predictive value of O-6-methylguanineDNA methyltransferase promoter methylation in glioblastoma patients treated with temozolomide. Clin Cancer Res (2004) 10:1871-4. doi:10.1158/ 1078-0432.CCR-03-0384

41. Paz MF, Yaya-Tur R, Rojas-Marcos I, Reynes G, Pollan M, Aguirre-Cruz L, et al. CpG island hypermethylation of the DNA repair enzyme methyltransferase predicts response to temozolomide in primary gliomas. Clin Cancer Res (2004) 10:4933-8. doi:10.1158/1078-0432.CCR-04-0392

42. Dunn J, Baborie A, Alam F, Joyce K, Moxham M, Sibson R, et al. Extent of MGMT promoter methylation correlates with outcome in glioblastomas given temozolomide and radiotherapy. Br J Cancer (2009) 101:124-31. doi:10.1038/sj.bjc.6605127

43. Khalili K, Del Valle L, Wang JY, Darbinian N, Lassak A, Safak M, et al. T-antigen of human polyomavirus JC cooperates with IGFIR signaling system in cerebellar tumors of the childhood-medulloblastomas. Anticancer Res (2003) 23:2035-41.

44. Khalili K, Del Valle L, Otte J, Weaver M, Gordon J. Human neurotropic polyomavirus, JCV, and its role in carcinogenesis. Oncogene (2003) 22:5181-91.

45. Hori R, Murai Y, Tsuneyama K, Abdel-Aziz HO, Nomoto K, Takahashi H, et al. Detection of JC virus DNA sequences in colorectal cancers in Japan. Virchows Arch (2005) 447:723-30. doi:10. 1007/s00428-005-0014-3

46. Murai Y, Zheng HC, Abdel Aziz HO, Mei H, Kutsuna T, Nakanishi Y, et al. High JC virus load in gastric cancer and adjacent non-cancerous mucosa. Cancer Sci (2007) 98:25-31. doi:10.1111/j.13497006.2006.00354.x

47. Coelho TR, Gaspar R, Figueiredo P, Mendonça C, Lazo PA, Almeida L. Human JC polyomavirus in normal colorectal mucosa, hyperplastic polyps, sporadic adenomas, and adenocarcinomas in Portugal. J Med Virol (2013) 85(12):2119-27. doi:10. 1002/jmv.23705

48. Kutsuna T, Zheng H, Abdel-Aziz HO, Murai Y, Tsuneyama K, Furuta I, et al. High JC virus load in tongue carcinomas may be a risk factor for tongue tumorigenesis. Virchows Arch (2008) 452:405-10. doi:10.1007/s00428-007-0534-0

49. Enam S, Del Valle L, Lara C, Gan DD, OrtizHidalgo C, Palazzo JP, et al. Association of human polyomavirus JCV with colon cancer: evidence for interaction of viral T-antigen and $\beta$-catenin. Cancer Res (2002) 62:7093-101.

50. Sadeghi F, Salehi-Vaziri M, Ghodsi SM, Alizadeh A, Bokharaei-Salim F, Saroukalaei ST, et al. Prevalence of JC polyomavirus large $\mathrm{T}$ antigen sequences among Iranian patients with central nervous system tumors. Arch Virol (2015) 160(1):61-8. doi 10.1007/s00705-014-2230-0

51. Noguchi A, Kikuchi K, Ohtsu T, Yoshiwara M, Nakamura Y, Miyagi Y, et al. Pulmonary tumors associated with the JC virus T-antigen in a transgenic mouse model. Oncol Rep (2013) 30(6):2603-8. doi:10.3892/or.2013.2782

52. Krynska B, Gordon J, Otte J, Franks R, Knobler $\mathrm{R}$, DeLuca A, et al. Role of cell cycle regulators in tumor formation in transgenic mice expressing the human neurotropic virus, JCV, early protein. J Cell Biochem (1997) 67:223-30. doi:10.1002/(SICI)1097-4644(19971101)67: 2<223::AID-JCB7>3.0.CO;2-Z

53. Shollar D, Del Valle L, Khalili K, Otte J, Gordon J. JCV T-antigen interacts with the neurofibromatosis type 2 gene product in a transgenic mouse model of malignant peripheral nerve sheath tumors. Oncogene (2004) 23:5459-67. doi: 10.1038/sj.onc. 1207728

54. Noch E, Sariyer IK, Gordon J, Khalili K. JC virus $\mathrm{T}$-antigen regulates glucose metabolic pathways in brain tumor cells. PLoS One (2012) 7(4):e35054. doi:10.1371/journal.pone.0035054

55. Bellizzi A, Anzivino E, Rodio DM, Palamara AT, Nencioni L, Pietropaolo V. New insights on human polyomavirus JC and pathogenesis of progressive multifocal leukoencephalopathy. Clin Dev Immunol (2013) 2013:839719. doi:10.1155/2013/ 839719

56. Hirsch HH, Kardas P, Kranz D, Leboeuf C. The human JC polyomavirus (JCPyV): virological background and clinical implications. APMIS (2013) 121:685-727. doi:10.1111/apm.12128

57. Shackelton LA, Rambaut A, Pybus OG, Holmes EC. JC virus evolution and its association with human populations. J Virol (2006) 80(20):9928-33.

58. Outteryck O, Zéphir H, Salleron J, Ongagna JC, Etxeberria A, Collongues $\mathrm{N}$, et al. JC-virus seroconversion in multiple sclerosis patients receiving natalizumab. Mult Scler (2013).

59. White FA III, Ishaq M, Stoner GL, Frisque RJ. JC virus DNA is present in many human brain samples from patients without progressive multifocal leukoencephalopathy. J Virol (1992) 66(10):5726-34.

60. Stoner GL. Polyomavirus models of brain infection and the pathogenesis of multiple sclerosis. Brain Pathol (1993) 3(3):213-27. doi:10.1111/j. 1750-3639.1993.tb00748.x

61. Boerman RH, Bax JJ, Beekhuis-Brussee JA, Medaer R, Bollen LE. JC virus and multiple sclerosis: a refutation? Acta Neurol Scand (1993) 87(5):353-5. doi:10.1111/j.1600-0404.1993.tb04116.x

62. Buckle GJ, Godec MS, Rubi JU, Tornatore C, Major EO, Gibbs CJ Jr, et al. Lack of JC viral genomic sequences in multiple sclerosis brain tissue by polymerase chain reaction. Ann Neurol (1992) 32(6):829-31. doi:10.1002/ana.410320622

63. Ferrante P, Omodeo-Zorini E, Caldarelli-Stefano R, Mediati M, Fainardi E, Granieri E, et al. Detection of JC virus DNA in cerebrospinal fluid from multiple sclerosis patients. Mult Scler (1998) 4(2):49-54. doi:10.1191/135245898678919528

64. Alvarez-Lafuente R, García-Montojo M, De Las Heras V, Bartolomé M, Arroyo R. JC virus in cerebrospinal fluid samples of multiple sclerosis patients at the first demyelinating event. Mult Scler (2007) 13(5):590-5. doi:10.1177/ 1352458506073116

65. Major EO, Frohman E, Douek D. JC viremia in natalizumab-treated patients with multiple sclerosis. N Engl J Med (2013) 368(23):2240-1. doi:10. 1056/NEJMc1214233

66. Tan CS, Koralnik IJ. Progressive multifocal leukoencephalopathy and other disorders caused by JC virus: clinical features and pathogenesis. Lancet Neurol (2010) 9(4):425-37. doi:10.1016/ S1474-4422(10)70040-5

67. Oberndorfer S, Ruzin PC, Grisold W. Concomitant radiochemotherapy in a patient with multiple sclerosis and glioblastoma. Clin Neuropathol (2008) 27:346-50. doi:10.5414/NPP27346

68. Hofer S, Linnebank M, Weller M, Bahmanyar S, Montgomery SM, Hillert J, et al. Cancer risk among patients with multiple sclerosis and their parents. Neurology (2010) 74:614-5. doi:10.1212/ WNL.0b013e3181c777b7

69. Vollmer T. The natural history of relapses in multiple sclerosis. J Neurol Sci (2007) 256(Suppl 1):S5-13. doi:10.1016/j.jns.2007.01.065

70. Pelletier D, Hafler DA. Fingolimod for multiple sclerosis. N Engl J Med (2012) 366(4):339-47. doi:10.1056/NEJMct1101691

71. Estrada-Bernal A, Palanichamy K, Ray Chaudhury A, Van Brocklyn JR. Induction of brain tumor stem cell apoptosis by FTY720: a potential therapeutic agent for glioblastoma. Neuro Oncol (2012) 14:405-15. doi:10.1093/neuonc/nos005

72. Fox RJ, Miller DH, Phillips JT, Hutchinson M, Havrdova E, Kita M, et al. Placebo-controlled phase 3 study of oral BG-12 or glatiramer in multiple sclerosis. N Engl J Med (2012) 367(12):1087-97. doi:10.1056/NEJMoa1206328

73. Ghods AJ, Glick R, Braun D, Feinstein D. Beneficial actions of the anti-inflammatory dimethyl fumarate in glioblastomas. Surg Neurol Int (2013) 4:160. doi:10.4103/2152-7806.123656

Conflict of Interest Statement: The authors declare that the research was conducted in the absence of any commercial or financial relationships that could be construed as a potential conflict of interest.

Received: 19 November 2014; accepted: 17 February 2015; published online: 04 March 2015.

Citation: Plantone D, Renna $R$, Sbardella $E$ and Koudriavtseva $T$ (2015) Concurrence of multiple sclerosis and brain tumors. Front. Neurol. 6:40. doi: 10.3389/fneur.2015.00040

This article was submitted to Multiple Sclerosis and Neuroimmunology, a section of the journal Frontiers in Neurology.

Copyright (c) 2015 Plantone, Renna, Sbardella and Koudriavtseva. This is an open-access article distributed under the terms of the Creative Commons Attribution License (CC BY). The use, distribution or reproduction in other forums is permitted, provided the original author(s) or licensor are credited and that the original publication in this journal is cited, in accordance with accepted academic practice. No use, distribution or reproduction is permitted which does not comply with these terms. 